\title{
Research on Optimal Coordination and Algorithms of Microprocessor-based Inverse Time Backup Protection
}

\author{
Xiaoyang Wang ${ }^{1,2^{*}}$, Zhongqing $\mathrm{LI}^{1,2}$ \\ ${ }^{1}$ China Electric Power Research Institute, Haidian District, Beijing, 100192, China \\ ${ }^{2}$ The State Key Laboratory for security and energy saving, Haidian District, Beijing, 100192, China
}

\begin{abstract}
Backup protection plays an important role in the safe operation of power grid, and it has important research value in the field of power system relay protection. Firstly, the research status and development opportunities of inverse time limit protection are analyzed, and then the best cooperation between inverse time limit protection and distance protection is discussed theoretically. According to the time constraint relationship in the protection range, an objective function satisfying the selectivity and speed is proposed. Secondly, in view of the difficulty in calculating the inverse time characteristic curve, a processing algorithm combining Taylor expansion method and look-up table method is proposed. Finally, the effectiveness and practicability of the method are verified by simulation experiments.
\end{abstract}

\section{Introduction}

In domestic power grid, overcurrent protection is widely used because of high reliability, low cost, fast action and other characteristics. Usually, overcurrent protection can be divided into definite time overcurrent protection and inverse time overcurrent protection [1]. Although inverse time overcurrent protection has a lot of advantages, current protection of domestic power grid is still mainly composed of definite time overcurrent protection [2]. This is because that the time-current characteristics adopted by inverse time overcurrent protection are nonlinear function and difficult to achieve in traditional induction type relays. Nevertheless, with the rapid development of computer technology, microprocessorbased relays are widely applied in the field of relay protection, and inverse time overcurrent protection will be easily realized in relay protection device.

To give full play to the excellent characteristics of microprocessor-based inverse time overcurrent protection and generalize the actual engineering application, a lot of electricity scholars and experts have carried out extensive research and discussion, and proposed multiple characteristics of inverse time overcurrent relays for different occasions [3,4]. In the aspect of optimal coordination of inverse time overcurrent protection, experts from abroad have put forward a series of cooperation mechanisms and setting calculation methods [5-7]. In recent years, some domestic scholars have done some research work about inverse time protection from the perspective of theories and proposed optimal setting models of inverse time protection based on uncertainty and optimization theory, but the present research is still not comprehensive [8].
Under the above background, this paper puts forward a kind of optimal coordination model and microprocessor-based algorithms of inverse time overcurrent protection. In order to optimize coordination performance of power system microprocessor-based inverse time overcurrent protection devices, the coordination difficulties of inverse time overcurrent protection and distance protection are discussed. Then a microprocessor-based inverse time processing algorithm combines Taylor expansion method and look-up table method is put forward, which can effectively improve the fitting accuracy.

\section{Coordinating Models of Inverse Time Overcurrent Protection}

At present, IEC255-3 standard inverse time characteristic curve is widely used in domestic power grids [3], which mainly includes general inverse time, very inverse time, super inverse time and long inverse time. For the convenience for study, this paper adopts unified inverse time characteristic for the entire network relay protection devices and the general inverse time characteristic equation is introduced as follows:

$$
t=\frac{0.14 K}{\left(I / I_{p}\right)^{0.02}-1}
$$

Where $K$ is the time setting constant, $I_{p}$ is the pickup current, $I$ is the fault current and $t$ is the operation time. 


\subsection{Optimal Coordination between Inverse Time Overcurrent Relays}

Fig.1 shows the coordination rules between inverse time overcurrent relays. In the radial network, this paper assumes that there is a short-circuit fault in line BC. So the inverse time characteristic of protection $\mathrm{m}$ near bus $\mathrm{B}$ is the curve tm, the protection b near bus A is the backup protection of $\mathrm{m}$ and inverse time characteristic is the curve tb. In order to coordinate inverse time overcurrent protection $\mathrm{m}$ with $\mathrm{b}$, the $\mathrm{F} 1$ and $\mathrm{F} 2$ are adopted as constraint limit points, where the position of $\mathrm{F} 1$ is at the exit of protection $\mathrm{m}$ and the position of $\mathrm{F} 2$ is at the end of line $\mathrm{BC}$.

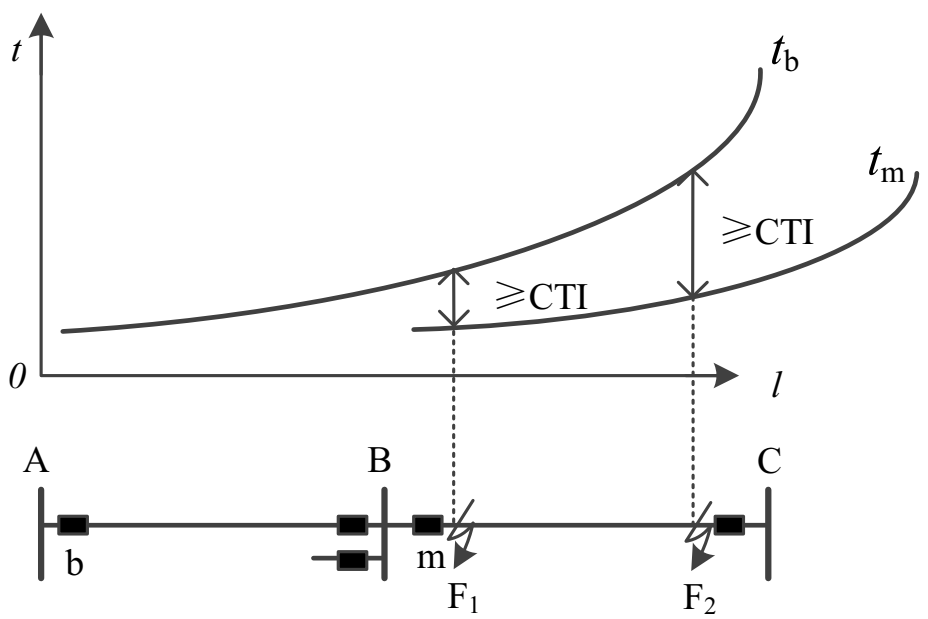

Fig.1 Coordination between inverse time overcurrent relays

In order to let the coordination between protection $\mathrm{m}$ and $b$ satisfies selectivity, the operation time of protection $\mathrm{m}$ and $\mathrm{b}$ must have range in the operation scope of protection $b$, namely the following constraints must be established:

$$
\begin{aligned}
& t_{\mathrm{b}}\left(\mathrm{F}_{1}\right)-t_{\mathrm{m}}\left(\mathrm{F}_{1}\right) \geq \mathrm{CTI} \\
& t_{\mathrm{b}}\left(\mathrm{F}_{2}\right)-t_{\mathrm{m}}\left(\mathrm{F}_{2}\right) \geq \mathrm{CTI}
\end{aligned}
$$

Where CTI is the coordination time interval and includes the circuit breaker tripping time, operation time errors of protective relays and margin time.

\subsection{Optimal Coordination between Inverse Time Overcurrent Protection and Distance Protection}

Distance protection adopts three-zone ladder delay characteristics widely at present. In general, the setting operation time of zone-1 distance protection is very short, but the setting operation time of zone-3 distance protection is too long because of setting coordination, thus it is not appropriate for zone- 3 distance protection to coordinate with inverse time overcurrent protection. On the other hand, zone-2 distance protection is the quickaction zone with fixed time delay about $0.3-0.6 \mathrm{~s}$, and can coordinate with inverse time overcurrent protection in operation time limit and protection scope. Therefore, coordination between inverse time overcurrent protection and zone II distance protection is mainly considered as follows.

Optimal coordination between inverse time overcurrent protection and zone- 2 distance protection is showed in Fig.2, where $t_{\mathrm{Z} 1}, t_{\mathrm{Z} 2}$ and $\mathrm{t}_{\mathrm{Z} 3}$ are the operation time of zone-1, zone- 2 and zone- 3 . In order to coordinate inverse time overcurrent protection with zone-2 distance protection, the F3 and F4 are adopted as the main constraint limit points, where the position of $\mathrm{F} 3$ is at the end of zone- 2 protection scope of distance protection $b$ and the position of F4 is at the end of zone- 1 protection scope of distance protection $\mathrm{m}$.

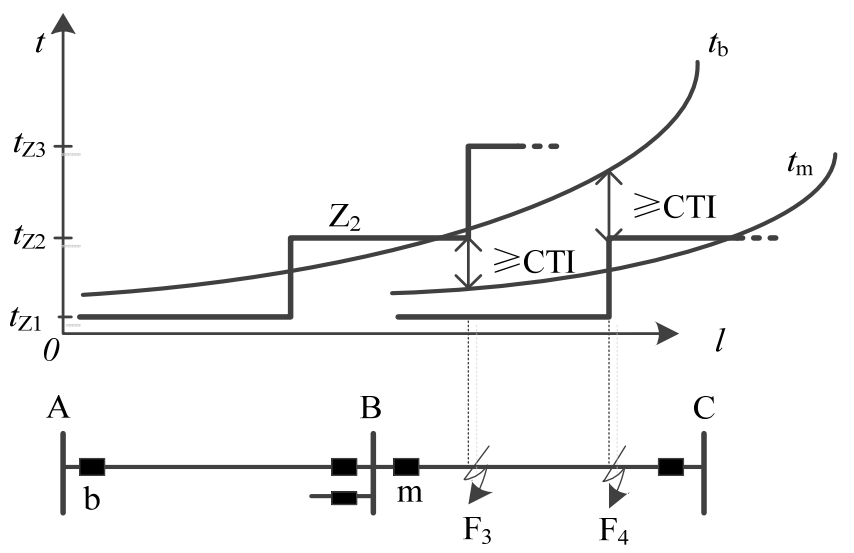

Fig.2 Coordination between inverse time overcurrent protection and distance protection 
The operation time of inverse time overcurrent protection $b$ is $\mathrm{tb}(\mathrm{F} 4)$ at point $\mathrm{F} 4$. Because the position of $\mathrm{F} 4$ is in the protection scope of distance protection $\mathrm{m}$, so the operation time of inverse time overcurrent protection must be slower than distance relay as the main protection, namely the function constraint must be met:

$$
t_{\mathrm{b}}\left(\mathrm{F}_{4}\right)-t_{\mathrm{Z} 2} \geq \mathrm{CTI}
$$

At the other constraint point $\mathrm{F} 3$, because the zone-2 distance relay of protection $b$ is the backup protection of inverse time overcurrent protection $\mathrm{m}$, so the operation time of zone-2 distance relay must be slower than inverse time overcurrent protection, namely the function constraint must be met:

$$
t_{\mathrm{Z} 2}-t_{\mathrm{m}}\left(\mathrm{F}_{3}\right) \geq \mathrm{CTI}
$$

In general, the operation time $\mathrm{t}_{\mathrm{Z} 2}$ of zone- 2 distance protection is given, so the selection of $t_{\mathrm{z} 2}$ will affect the protection setting result. Thus, $\mathrm{t}_{\mathrm{Z} 2}$ must be variable and have an optimal solution. The constraint of $t_{\mathrm{Z} 2}$ is defined as follows:

$$
t_{\mathrm{Z} 2 \min } \leq t_{\mathrm{Z} 2} \leq t_{\mathrm{Z} 2 \max }
$$

\subsection{Objective Function Model}

For a sort of system failure $i$, the difference of operation time of superior and inferior protection devices can be described as follows:

$$
\mathrm{CTI}_{i j}=t_{i}-t_{j}
$$

Where ti is the operation time of superior protection device, $t \mathrm{j}$ is the operation time of inferior protection device. In order to make the relays have selectivity when fault happens, the time difference constraint violation number is defined.

$$
N_{i j}= \begin{cases}1 & \mathrm{CTI}_{i j}<\gamma \\ 0 & \mathrm{CTI}_{i j}>\gamma\end{cases}
$$

Where $\gamma$ is the given time difference.

In order to ensure the speed of protection devices, the difference of operation time must be as small as possible, so the coordination optimization objective function of microprocessor-based inverse time overcurrent protection can be expressed as follows:

$$
\min \left(\alpha \sum_{i} \sum_{j} N_{i j}+\beta \sum_{i} \sum_{j}\left|\mathrm{CTI}_{i j}-\gamma\right|\right)
$$

Where $\alpha$ and $\beta$ are the weight coefficients

\subsection{Algorithm of Microprocessor-based Inverse Time Characteristics}

The general expression of IEC255-3 standard inverse time characteristic curves is $t=Q /\left[\left(I / I_{p}\right)^{r}-1\right]$, where $\mathrm{Q}$ and $\mathrm{r}$ are constants. Because there is a delay for the calculation of inverse time relay, and the fault current changes frequently, therefore the above expression must be changed as follows:

$$
Q=\left[\left(I / I_{p}\right)^{r}-1\right] t=\int_{0}^{t}\left[\left(i(t) / I_{p}\right)^{r}-1\right] d t=\Delta t \sum_{\zeta=0}^{N-1}\left[\left(i(\zeta) / I_{p}\right)^{r}-1\right]
$$

Where $\Delta \mathrm{t}$ is the sampling interval, $\mathrm{N}$ is the hits.

For the calculation of accumulative value $\left(I / I_{p}\right)^{r}$, when $r$ is 1,2 or the other integer, the value can be easily calculated, but when $r$ is 0.02 , it is a difficult work to calculate directly. At present, three algorithms are adopted usually, namely look-up table method, curve fitting method and Taylor expansion method. In order to use look-up table method to calculate operation time, it is necessary to deposit the calculated operation time into EPROM in advance. If the calculated fault current is not the point value stored in the table, the linear interpolation method is adopted to calculate approximately, but the computing speed is very slow, and the calculation accuracy depends entirely on the precision of the table and the linear fitting degree of inverse time curve. Curve fitting method usually adopts a formula to fit different kinds of characteristic curves. The fitting precision is related to subsection number, counts of each subsection, subsection strategy and location of the observation point. Therefore, in order to achieve the satisfactory accuracy, a lot of works need to be done. Taylor expansion method adopts Tailor formula to fit inverse time curve, the calculation precision can be guaranteed and the fitting error is relatively small, so the method is widely used in microprocessor-based relays. On the basic of Taylor expansion method, a new inverse time characteristic method is proposed as follows.

Let the expression $\left(I / I_{p}\right)^{r}=\left(I / I_{p}\right)^{V}\left(I / I_{p}\right)^{U}$, where $\mathrm{r}=\mathrm{V}+\mathrm{U}$, $\mathrm{V}$ is the integer part of $\mathrm{r}$ and $\mathrm{U}$ is the decimal part, $0 \leq U<1$. $\left(I / I_{p}\right)^{V}$ is easy to realize, so the key part is to calculate $f(x)=x^{U}$, and $x>1$.

$$
f(x)=x^{U}=\left[(1+a) 2^{n}\right]^{U}=\left(2^{U}\right)^{n}(1+a)^{U}
$$

Where $0 \leq a<1, \mathrm{n}$ is a nonnegative integer. In general, $(1+a)^{U}$ needs to be expanded with Taylor series. Considering the precision is higher when a is more close to 0 , a is divided into 8 segments with the step size 0.125 in the scope from 0 to 1 . So the calculation formula within $(u-1) \times 0.125 \leq a<u \times 0.125$ can be presented as follows:

$$
(1+a)^{U}=\left(1+a_{1}+\frac{u-1}{8}\right)^{U}=\left(\frac{u+7}{8}+a_{1}\right)^{U}=\left[\frac{u+7}{8}\left(1+\frac{8}{u+7} a_{1}\right)\right]^{U}=\left(\frac{u+7}{8}\right)^{U}\left(1+\frac{8}{u+7} a_{1}\right)^{U}
$$

Where the integer $u \in[1,8], 0 \leq a_{1}<0.125$. Because $0 \leq 8 a_{1} /(u+7) \leq a_{1}<0.125$, so the calculation error can be reduced greatly under the condition of fewer Taylor series expansions. In addition, $2^{U}$ and $[(u+7) / 8]^{U}$ can be acquired by look-up table method.

\subsection{Simulation Analysis}

To better validate the effectiveness of the microprocessor-based inverse time characteristic algorithm, general inverse time characteristic curve is adopted in this paper to do the example simulation 
analysis. Let $\mathrm{K}$ is 1 in Eq.1 and third order Tailor expansion formula is used to simulate characteristic curve, calculate operation time of inverse time relays and

Table 1 Operation time of inverse time overcurrent protection

\begin{tabular}{cccc}
\hline$I / I_{p}$ & $\begin{array}{c}\text { theoretical value } \\
/ s\end{array}$ & $\begin{array}{c}\text { simulation } \\
\text { results } / s\end{array}$ & error/\% \\
\hline 1.1 & 73.374 & 73.357 & -0.023 \\
\hline 1.2 & 38.324 & 38.323 & -0.003 \\
\hline 1.4 & 20.734 & 20.734 & 0 \\
\hline 2.1 & 9.365 & 9.365 & 0 \\
\hline 9.5 & 3.040 & 3.040 & 0 \\
\hline 19.3 & 2.296 & 2.296 & 0 \\
\hline
\end{tabular}

It can be seen from Table 1 that the proposed algorithm can accurately calculate the operation time of inverse time overcurrent protection, and the value is very close to the theoretical value, so the method has a good application prospect.

\section{Summary}

In this paper, the research status and development opportunities of inverse time overcurrent protection are analyzed, then an optimal coordination between inverse time overcurrent protection and distance protection is theoretically discussed, and a model is proposed. At last, a processing algorithm of microprocessor-based inverse time characteristic curve is put forward, the validity the proposed method is testified by simulation test.

\section{Acknowledgments}

This paper is one of the phased achievements of the science and technology project "Key technology and application research of large power grid setting calculation" of China Electric Power Research Institute.

\section{References}

1. Karegar H K, Abyaneh H A, Al-Dabbagh M. A flexible approach for overcurrent relay characteristics simulation[J]. Electric Power Systems Research, 2003, 66(3): 233-239.

2. Huang Yanquan, Xiao Jian, Cai Yong, et al. Application of a new time-current characteristics of microcomputer-based inverse time overcurrent relay protection $[\mathrm{J}]$. Automation of Electric Power Systems, 2003, 27(23): 71-73.

3. Sharaf H M, Zeineldin H H, Ibrahim D K, et al. A proposed coordination strategy for meshed distribution systems with DG considering userdefined characteristics of directional inverse time overcurrent relays $[\mathrm{J}]$. Electrical Power and Energy Systems, 2015, 65(10): 49-58.

4. Wang Wentao, Tai Lengling, Zheng Xiaodong, et al. An Impedance Protection Scheme for Feeders of compare with the theory operation time. The simulation result is shown in Table 1.

Active Distribution Networks[J]. IEEE Trans on Power Delivery, 2014, 29(4): 1591-1602.

5. Chabanloo R M, Abyaneh H A, Kamangar S S H. Optimal Combined Overcurrent and Distance Relays Coordination Incorporating Intelligent Overcurrent Relays Characteristic Selection[J]. IEEE Trans on Power Delivery, 2011, 26(3): 1381-1391.

6. Ojaghi M, Sudi Z, Faiz J. Implementation of full adaptive technique to optimal coordination of overcurrent relays[J]. IEEE Trans on Power Delivery, 2013, 28(1): 235-244.

7. Farzinfar M, Jazaeri M, Razavi F. A new approach for optimal coordination of distance and directional over-current relays using multiple embedded crossover PSO $[\mathrm{J}]$. Electrical Power and Energy Systems, 2014, 61(10): 620-628.

8. Mao Jinqing, Wang Peng. Discussion of microprocessor-based protection equipment on setting calculation simplification $[\mathrm{J}]$. Electric Power Automation Equipment, 2004, 24(11): 94-98. 